\title{
TREATMENT OF FRACTURES IN GENERAL PRACTICE
}

BY

HUGH CANE, M.B., B.Chir.

AND

\section{W. M. JORDAN, B.M., B.Ch., D.Obst.R.C.O.G.}

General Practitioners, Bungay, Suffolk

"It has become increasingly clear that the medical services throughout the country are inadequate to deal with the growing number of accidents." These are the opening words of the Interim Report of the Accident Services Review Committee (Osmond-Clarke et al., 1961), which was established jointly by seventeen medical and surgical organizations to review the existing accident services, and to recommend the lines on which they should be improved and developed.

The report proposes a comprehensive regional accident service on a three-tier scheme, with one specially equipped central accident unit, several dispersed accident units, and a peripheral casualty service for the treatment of minor injuries. It states that for every major injury there are at least a hundred minor injuries which require immediate and efficient treatment, and it recognizes the key role which can be played by the general-practitioner cottage hospital in the peripheral service. "The local practitioner will be as much a part of the accident service as the staff of the central unit."

If this vision of the future is to be translated into reality it is important to consider in concrete terms the function of the peripheral casualty service. The general practitioner is daily accustomed to assume responsibility for the treatment of most major diseases, and, granted the facilities and time required, there is no reason why he should not be fully responsible for the treatment of all minor injuries. It is indeed better both for his patients and for the overburdened central hospital that he should do so.

What, then, constitutes a minor injury? Which injuries are better treated by the general practitioner, and which ought to be referred to accident units? Such questions can best be considered by narrowing the problem down to more specific terms. Are all fractures major injuries requiring specialist treatment? This can hardly be so when it is realized that so many are at present efficiently treated by casualty officers and orthopaedic house-surgeons. "Many fractures can be as well treated by a simple M.B. as by a F.R.C.S." (Perkins, 1958).

Several common types of fractures are eminently suitable for treatment under conditions of general practice provided $x$-ray facilities and physiotherapy are available. It is certainly to the patient's advantage to have prompt treatment on the spot and follow-up reviews at his home or the family doctor's surgery. Of course many major fractures, particularly those that are compound or involve joints, must be referred to the orthopaedic surgeon at a central hospital. Most roadaccident fractures with associated injuries will come into this category. Country doctors are, however, well aware of the frustrations caused to their patients by delays due to distance, lack of transport, overworked fracture clinics, and inadequate hospital information.

\section{Description of the Practice}

The practice is based at Bungay, a small market town on the border between Norfolk and Suffolk, and embraces the surrounding countryside within a radius of five to seven miles ( 8 to $11 \mathrm{~km}$.). The town, of 3,500 inhabitants, acts as a professional, business, and shopping centre for the farming community and also provides employment in printing works, maltings, sawmills, and a shoe factory. Another similar practice of two partners covers the same area, and they also treat their own minor fractures. Bungay is 15 miles $(24 \mathrm{~km}$.) from the nearest central hospital at Norwich.

Our practice is conducted from a central surgery and we have the use of a small cottage hospital where there is a portable $x$-ray apparatus which we operate. We also have direct access to the physiotherapy department at Beccles Cottage Hospital, six miles $(9.6 \mathrm{~km}$.) away. The Norfolk and Norwich Hospital provides a complete range of medical and surgical services with three consultant orthopaedic surgeons on the staff. They are, however, working at full capacity, with resulting delays of two to three months for orthopaedic out-patient appointments.

It has always been the custom here for the local doctors to treat minor fractures without reference to Norwich, although we are at liberty to send all cases to the orthopaedic department if we wish to do so. Selection of fractures is as vital to the success of treatment in general practice as it is in the selection of maternity cases. Although many general practitioners have published clinical studies of selection in midwifery we believe none have yet published a similar survey of fracture selection. In order to clarify the problem we have analysed those cases which we have personally $x$-rayed and treated, as well as those we have referred to the Norwich hospitals.

\section{Method and Results of Study}

We first studied the total fracture incidence in this practice during 1959. During the year there were 39 fractures, giving an incidence of 10.6 per 1,000 patients at risk. Of these 39 we $x$-rayed 20 -treating 18 and referring 2 to hospital (Table I). The remaining 19 were $x$-rayed at Norwich or Lowestoft hospitals, where 11 were admitted, six treated as out-patients, and two referred back to us for treatment (Table II). We were therefore able to treat $50 \%$ of the total number of fractures occurring during that year. Only two patients were taken direct to hospital without having been seen

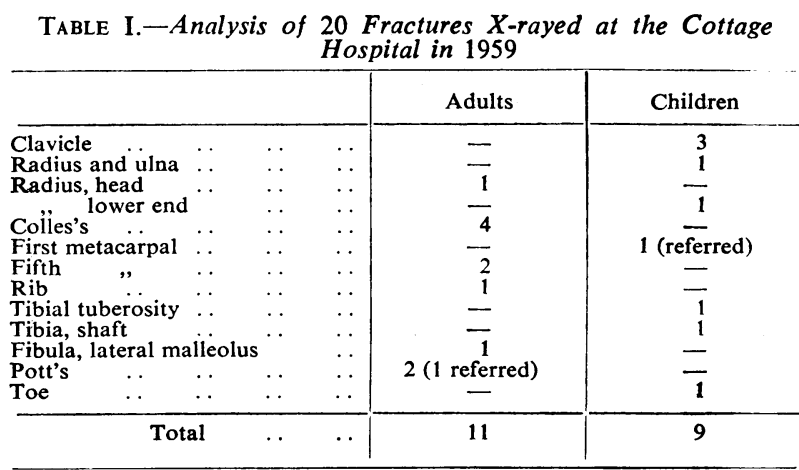


previously by us, one being injured in a road accident and the other in a trawler at sea.

We next prepared a complete clinical analysis of the types of fracture treated. We examined 195 consecutive $x$-ray films which we took during the decade 1952-61: 100 were fracture-positive and 95 fracture-negative. Several of the latter included dislocations we $x$-rayed to exclude associated fractures. Of the negative radiographs 59 were in adults and 36 in children (Table III).

TABLE II.-Analysis of 19 Fractures X-rayed in 1959 at Central

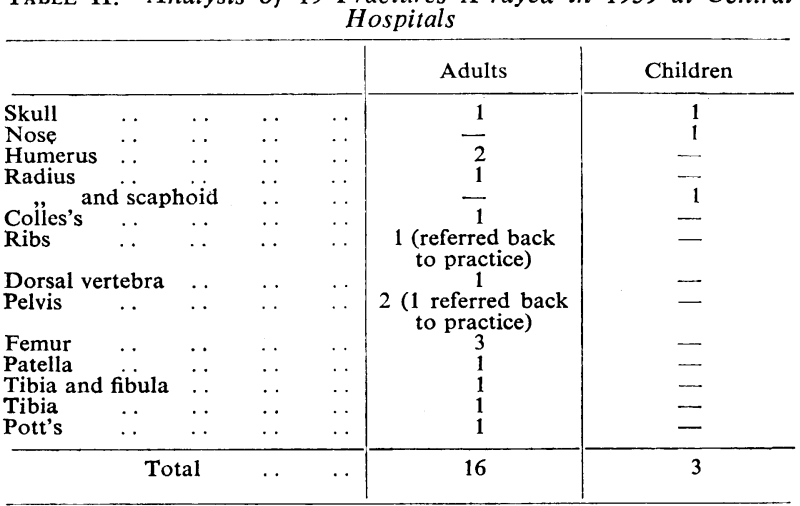
TABLE III.-Analysis of 95 Consecutive Negative X-ray Films
Taken at the Cottage Hospital

\begin{tabular}{|c|c|c|c|c|c|c|c|}
\hline & & Adults & Children & & & Adults & Children \\
\hline $\begin{array}{l}\text { Clavicle } \\
\text { Shoulder } \\
\text { Elbow } \\
\text { Forearm } \\
\text { Wrist } \\
\text { Hand } \\
\text { Finger }\end{array}$ & $\begin{array}{l}\cdots \\
\cdots \\
\cdots \\
\cdots \\
\cdots \\
\cdots\end{array}$ & $\begin{array}{l}\overline{8} \\
1 \\
9 \\
1 \\
6\end{array}$ & $\begin{array}{l}2 \\
2 \\
4 \\
6 \\
3 \\
3\end{array}$ & $\begin{array}{l}\text { Thumb } \\
\text { Leg } \\
\text { Knee } \\
\text { Ankle } \\
\text { Foot } \\
\text { Toe }\end{array}$ & $\begin{array}{l}\ldots \\
\cdots \\
\cdots \\
\cdots \\
\cdots\end{array}$ & $\begin{array}{r}4 \\
2 \\
15 \\
10 \\
3\end{array}$ & $\begin{array}{r}2 \\
1 \\
1 \\
7 \\
5 \\
-\end{array}$ \\
\hline & & & & Total & & 59 & 36 \\
\hline
\end{tabular}

The 100 consecutive positive fractures were then considered in detail: they included 54 adults (Table IV) and 46 children (Table V). No statistical conclusions can be drawn from these figures regarding the incidence of certain fractures occurring at different ages, because they were selected for their suitability for treatment in general practice. Most children's fractures carry a good prognosis: they comprised $46 \%$ of those we treated, but only $31 \%$ of all fractures seen.

Further consideration of the types of fracture treated shows the preponderance of Colles's fractures in adults and fractures of the clavicle, the radius alone, or the radius and ulna in children. The wide variety treated is illustrated by 21 different types in adults and 14 in children, thus reflecting some of the interest and scope of this work.

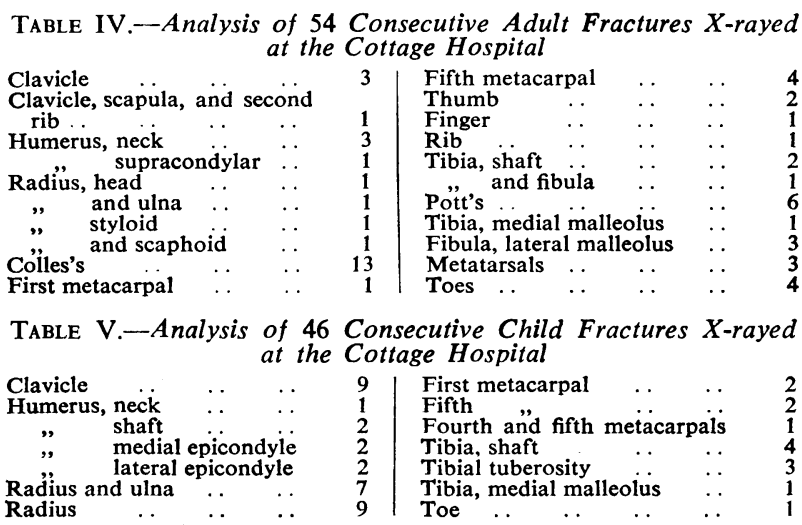

Reduction under general anaesthesia was required for $25 \%$ of the fractures we treated, both in adults and in children. Local anaesthesia was used occasionally when the other partner was not available. Approximately half of those treated did not require reduction, but were simply supported by a plaster slab, adhesive strapping, or a sling.

Treatment in the practice achieved excellent results in all the children. No child was absent from school for more than two months, and none had any residual disability. All the adults were treated with very good results, and with only two exceptions all returned to work within three months. One housewife developed some subluxation of a Pott's fracture after reduction and was referred to hospital for further treatment. Another woman sustained a comminuted fracture of the tibia and fibula at the ankle-joint, and as reduction proved unstable she was referred to an orthopaedic surgeon, who performed an arthrodesis. In retrospect it seems that we would have been wiser not to have attempted treating these two patients.

\section{Discussion}

The first family doctor to study the total incidence of fractures was McGregor (1953). He found in his mixed suburban-rural practice at Hawick, in Scotland, a fracture rate of 10.1 per 1,000 patients, and that fractures comprised $11.1 \%$ of all the accidents about which he was consulted. The statistical incidence of fractures was studied in detail by Logan and Cushion (1958), who analysed the total morbidity seen by 171 doctors in 106 different practices in one year: they found that the patient-consulting rate for fractures in the eastern region of England was 10.5 per 1,000 per annum, and this agrees with our findings (10.6 per 1,000).

These results can be applied to other types of practice in other areas of the country, so that any practitioner can estimate the total load of fracture work which his own practice is likely to carry. The average annual patient-consulting rate for fractures in all practices was 9 per 1,000 , but this figure conceals considerable regional variations. The highest incidence was found in the south-western (12.0), northern (11.1), and eastern (10.5), while the lowest incidence was in the north-western (7.5), midland (8.3), and London and south-eastern regions (8.5). There were also differences between the urban and rural fracture rates: they increased from 8.3 in the conurbations to 9.3 in urban areas of under 50,000 population, while the highest figures were found in rural districts (10.6). Further variations occur in the age and sex incidence. Table VI illustrates the contribution of both these factors to the total number of new fractures occurring annually in any one practice. The highest fracture incidence was found in young adult males (12.3) and elderly females (16.2).

An approximate estimate of the extra volume of work likely to be shouldered by a general practitioner who treats his own fractures can be obtained by measure-

TABLE VI.-Patient-Consulting Rate for Fractures per 1,000

\begin{tabular}{l} 
Population Per Annum (Logan and Cushion, 1958) \\
\hline \\
\hline
\end{tabular}


ment of the consultation rate, bearing in mind the extra time needed at the first consultation. Logan and Cushion (1958) found that on an average every fracture patient consulted his doctor four times. In the under15 age-group children required an average of only two consultations, while in those 65 and over the average was five. Our own fracture-consultation rates are higher than this, though after the initial treatment reviews are usually brief. Mention must also be made of the extra time involved in $x$-raying and treating suspected fractures which prove negative.

The present-day role of the family doctor in the treatment of fractures varies according to the geographical nature of his practice. Fry (1961) states that "the practitioner will have to refer some $90 \%$ of his fractures if he works in a built-up area." This seems to be the current practice of most urban practitioners, and it must add to the overcrowding of orthopaedic departments throughout the country. In a survey of a Birmingham hospital casualty department Crombie (1959) divided fracture patients into those who could have been treated by a general practitioner and those who should have been referred to hospital. He considered that $30 \%$ could have been treated by their own doctors, and included those he thought need not have been $x$-rayed and those where the treatment would have been the same whether there was a fracture or not-for example, ribs.

McGregor (1961) recorded his experience in a small country town having a cottage hospital, and discussed the treatment of 3,720 accidents of all types occurring over a period of $11 \frac{1}{2}$ years. He divides them into three groups: $(a)$ those which the family doctor should deal with entirely himself ; $(b)$ those which he should treat if he has facilities in his surgery or cottage hospital; and (c) those which need specialist treatment. He found that only 111 fell into the third group and he had personally treated the rest. Although he does not specify the number of fractures included, calculation of the incidence from his earlier paper would give a total of 284 , which means that he treated $60 \%$ of his cases.

It therefore seems that, in the country at least, the interested doctor can treat most of his accident cases, including about half the fractures. He must, however, have access to an $x$-ray machine, and this usually means a cottage hospital.

Perkins (1958) has published practical guidance on fracture selection by introducing a three-star classification: one-star can be safely treated by the patient's own doctor, two-star by a general-practitioner surgeon in a cottage hospital, and three-star by an orthopaedic surgeon. We agree in general with this classification, and in fact $95 \%$ of the fractures we treated are included in his one-star list.

Why have many general practitioners given up the treatment of fractures? One reason is the lack of official encouragement resulting from the capitation system of payment under the National Health Service. The principle of financial incentive for extra services is recognized in midwifery and anaesthetics, and we believe it should be extended to radiography and minor surgery. At present general practitioners who use a private $x$-ray machine, as we do, are not even reimbursed by the N.H.S. for the cost of films, let alone paid for their time and skill.

Another difficulty in fracture treatment is that many of us lack the necessary facilities, and these are likely to be further reduced by the closure of existing cottage hospitals. If they are indeed doomed to disappear, despite the recommendations of the Accident Services Review Committee, we would urge the provision of fully equipped general-practitioner diagnostic and treatment centres. Only thus can the district hospitals be spared unnecessary work and the family doctor enabled to fulfil his proper role in the treatment of accidents.

\section{Summary}

An account is presented of the diagnosis, selection, and treatment of fractures in a semi-rural practice. Out of a total annual incidence of 10.6 fractures per 1,000 patients at risk we $x$-rayed and treated $50 \%$ without reference to a central hospital. Types of fracture suitable for treatment by family doctors are illustrated by analysis of 100 cases.

The role of the general practitioner and the cottage hospital in the provision of a peripheral accident service is discussed, and certain administrative changes are suggested to encourage the mobilization of unused medical skills in the National Health Service.

\section{REFERENCES}

Crombie, D. L. (1959). J. Coll. gen. Practit., 2, 346.

Fry, J. (1961). "Symposium on Accident Management," Supplement to J. Coll. gen. Practit., 2, 1.

Logan, W. P. D., and Cushion, A. A. (1958). Morbidity Statistics from General Practice, vol. 1 (general). H.M.S.O., London from General Practice, vol. 1 (general). H.M.

McGregor, R. M. (1953). Brit. med. J., 2, 1306. (1961). “Symposium on Accident Management," Supplement to J. Coll. gen. Practit., 2, 1.

Osmond-Clarke, H., et al. (1961). Interim Report of Accident Services Review Committee. London.

Perkins, G. (1958). Fractures and Dislocations. Athlone, London.

Sir George Godber, speaking at the Conference of the Association of Hospital Management Committees of Northern Ireland on October 5, 1962, said: "There has been one quite important difference in our approaches which arises from the nature of services that were taken over in 1948. In England we had a large number of hospitals and a large number of hospital beds. . . . Here you were short of beds and of hospitals and so you had a more immediate need to proceed with the building of new hospitals than we experienced. There is an odd anomaly in this also that if you have a lot of old hospitals they are costly to run and you spend a great deal of money and energy in making what you have work; so you have neither the money nor the energy to go in immediately for largescale building. In fact, if you have hospitals you find greater difficulty in affording to keep them going and to do building than if you lack hospitals and do not have to pay for their upkeep while you are building new ones. This is not an apology for our own failure to build new ones but it does explain why there had to be an even greater sense of urgency about building here. ... I hope you will not think me unfairly critical if I say that this urgency to build inevitably led you into some actions that you probably would not contemplate if you were starting again now. For instance, all of us have seen your fine new hospital at Altnagelvin and, not so very far away, new mental hospital buildings. If you were starting again in Londonderry now, I do not think you would have planned those two hospitals separately, but rather you would have provided a composite hospital. If we had been in your shoes when those two hospitals were being planned we would have done exactly what you did. So I am certainly not saying that you ought to have approached the matter in a different way than you did. I will not say I am thankful for the fact that we could not build in the early stages of the Health Service, but I do say that our planning must be better now than it would have been a dozen years ago." 